\title{
Trauma Surgery Characterizing the delays in adequate thromboprophylaxis after TBI
}

\author{
Navpreet K Dhillon, Yassar M Hashim, Naomi Berezin, Felix Yong, Geena Conde, \\ Russell Mason, Eric J Ley
}

Department of Surgery, CedarsSinai Medical Center, Los Angeles, California, USA

Correspondence to Dr Eric J Ley; Eric.Ley@cshs.org

Received 21 January 2021 Revised 7 April 2021 Accepted 18 April 2021 (c) Author(s) (or their employer(s)) 2021. Re-use permitted under CC BY-NC. No commercial re-use. See rights and permissions. Published by BMJ.

To cite: Dhillon NK, Hashim YM, Berezin N, et al. Trauma Surg Acute Care Open 2021:6:e000686.

\section{ABSTRACT}

Background We sought to compare enoxaparin dosing for venous thromboembolism (VTE) prophylaxis in trauma patients with and without traumatic brain injury (TBI) to better understand the time and dose required to reach target anti-Xa levels. Our hypothesis was that patients with TBI have significant delays in the initiation of adequate pharmacological prophylaxis and require a higher enoxaparin dose than currently recommended. Methods The medical records of trauma patients who received enoxaparin dosing based on anti-Xa trough levels between August 2014 and October 2016 were reviewed. Patients were included if their anti-Xa trough level reached the target range $(0.1 \mathrm{JU} / \mathrm{mL}$ to $0.2 \mathrm{IU} / \mathrm{mL})$. Results A total of 163 patients had anti-Xa levels within the target range of which $41(25.2 \%)$ had TBI. Patients with TBI had longer delays before initiating enoxaparin (7.5 days vs. 1.5 days after admission, $p<0.01)$ and were more likely to receive unfractionated heparin prior to enoxaparin (46.3\% vs. $11.5 \%, \mathrm{p}<0.01)$. Anti-Xa levels reached the target range later in patients with TBI (11 days vs. 5 days after admission, $p<0.01$ ). Enoxaparin $40 \mathrm{mg}$ two times per day was the median dose required to reach the target anti-Xa levels for both cohorts. VTE rates were higher among patients with TBI (22.0\% vs. 9.0\%, $p=0.03)$. Four patients $(9.8 \%)$ had progression of their intracranial hemorrhage prior to receiving enoxaparin, although none progressed during enoxaparin administration.

Conclusion Among patients with TBI who reached target anti-Xa levels, 11 days after admission were required to reach a median enoxaparin dose of $40 \mathrm{mg}$ two times per day. Unfractionated heparin was used as pharmacological prophylaxis in about half of these patients. The delay in reaching the target anti-Xa levels and the use of unfractionated heparin likely contribute to the higher VTE rate in patients with TBI.

Level of evidence Level III, therapeutic.

\section{INTRODUCTION}

Compared with patients without traumatic brain injury (TBI), those with TBI are at a higher risk of developing venous thromboembolism (VTE). ${ }^{12}$ This increased risk may be partially attributed to delayed initiation of pharmacological prophylaxis secondary to the concern for progression of intracranial hemorrhage $(\mathrm{ICH}) .^{2}$ In addition, despite broad research that favors enoxaparin for VTE prophylaxis after TBI instead of unfractionated heparin, practice patterns for pharmacological prophylaxis remain widely variable. ${ }^{3-11}$ One study suggested unfractionated heparin dosed at $5000 \mathrm{U}$ three times a day was proposed as 'non-inferior' to enoxaparin, ${ }^{12}$ although more recently, enoxaparin $30 \mathrm{mg}$ two times per day was considered superior at the prevention of VTE. ${ }^{8} 1011$

The early initiation of enoxaparin is safe and associated with lower VTE rates. ${ }^{11}{ }^{13-25}$ Given that patients with TBI are at risk of ICH progression, the appropriate dosing of pharmacological prophylaxis remains elusive. The aim of this study was to compare the delay in reaching the target anti-Xa levels in trauma patients with and without TBI, as well as the median dose of enoxaparin required to achieve adequate VTE prophylaxis in patients with TBI. Our hypothesis was patients with TBI have significant delays in the initiation of adequate pharmacological prophylaxis and require higher doses of enoxaparin than currently recommended.

\section{PATIENTS AND METHODS}

\section{Study design}

We performed a retrospective review on trauma patients who received enoxaparin for pharmacological prophylaxis and reached target anti-Xa trough levels at our institution between August 2014 and October 2016. As this study required confirmation that an adequate enoxaparin dose was received, only trauma patients 18 years and older were included if their anti-Xa trough levels reached the target range $(0.1 \mathrm{IU} / \mathrm{mL}$ to $0.2 \mathrm{IU} / \mathrm{mL})$. Patients were excluded if no anti-Xa trough level reached the target range, which included patients who were discharged prior to receiving enoxaparin and those patients who had measured anti-Xa trough levels that did not reach the target range. Patients were also excluded if they did not receive enoxaparin due to renal impairment or heparin-induced thrombocytopenia, of if they were admitted with preexisting VTE or were on an anticoagulant or antiplatelet agent prior to admission. Patients were included if they were started on unfractionated heparin and then transitioned to enoxaparin dosing that reached target anti-Xa trough levels. If unfractionated heparin was administered, the dose was $5000 \mathrm{U}$ subcutaneously three times a day.

Clinical characteristics such as age, sex, race, Body Mass Index (BMI), body surface area (BSA), creatinine clearance $(\mathrm{CrCl})$, mechanism of injury, type of injury sustained, regional Abbreviated Injury Scale (AIS) scores, and Injury Severity Scores (ISS) were collected. Further details regarding pharmacological prophylaxis included the timing of 
enoxaparin or unfractionated heparin, the anti-Xa trough levels, and all dose adjustments required were also collected.

\section{Institutional VTE prophylaxis protocol}

During the study period, trauma patients were started on subcutaneous enoxaparin $30 \mathrm{mg}$ two times per day with adjustments made to reach a target anti-Xa trough level between 0.1 and 0.2 $\mathrm{IU} / \mathrm{mL}$. Trough levels were checked before the fourth consecutive dose as previously described. ${ }^{13}$ Briefly, the anti-Xa trough level was obtained within 1 hour prior to the fourth dose of enoxaparin, processed in our laboratory and followed by our pharmacy department. Dose adjustments were made in increments of $10 \mathrm{mg}$ two times per day, and anti-Xa levels were redrawn before the fourth dose of the new adjusted dose until the target range was reached.

The initiation of enoxaparin or unfractionated heparin was determined through a collaboration between the trauma and neurosurgical services with consideration given to the risk of bleeding, ICH, and anticipated surgical interventions. Once initiated, pharmacological prophylaxis could be held for operative procedures or suspected bleeding risk based on clinical judgment. Sequential compression devices were used for all patients unless specifically contraindicated by extremity injury. During the study period, the guidelines at our institution for patients with TBI recommended pharmacological prophylaxis within 24-48 hours of a CT of the brain that demonstrated no progression of ICH. A repeat CT of the brain was obtained 6 hours after the previous study if the previous study demonstrated progression. Further imaging was also obtained if there was a change in mentation or a worsening neurological examination. After achieving an enoxaparin dose that reached the target anti-Xa trough range, all trauma patients underwent continued anti-Xa monitoring and adjustments.

\section{Outcome measures}

The primary outcomes were days after admission until enoxaparin initiation, days after admission required to reach the anti-Xa level target range, and median enoxaparin dose required to reach the target range. The secondary outcomes included incidence of VTE, diagnosed by duplex ultrasonography for deep vein thrombosis (DVT) and chest CT angiography (CTA) for pulmonary embolisms (PEs). Upper and lower duplex ultrasonography and chest CTA were ordered in symptomatic patients based on clinical suspicion of VTE. Proximal lower extremity DVTs included those in the popliteal, femoral, or iliac veins, whereas distal lower extremity DVTs were located below the knee. Other outcomes data included the rate of unfractionated heparin dosing, intensive care unit (ICU) and hospital length of stay (LOS), transfusion requirements, the rate of ICH progression, and mortality.

\section{Statistical analysis}

Data were analyzed using SPSS V.24 statistical software and are summarized as percentages for categorical variables and as medians with IQR for continuous variables. Comparisons of medians were conducted using t test or Mann-Whitney U test, where appropriate. Categorical variables were compared using Pearson $\chi^{2}$ test or Fisher exact test. A p value of $<0.05$ was considered statistically significant.

\section{RESULTS}

There were 4014 trauma patients reviewed during the study period from August 2014 to October 2016, of which 705 had
TBI and 3309 did not. Of the 163 trauma patients who reached the target anti-Xa trough range, $41(25.0 \%)$ had TBI. The cohorts were comparable with respect to age, sex, race, BMI, BSA, and $\mathrm{CrCl}$ (table 1). The median ISS was 18 in the study population, with patients with TBI having a higher ISS than patients without TBI (26 vs. $17, \mathrm{p}<0.01)$.

During the study period, all brain trauma was the result of blunt injury. There was no difference between the specific mechanism resulting in blunt injury between TBI and non-TBI trauma patients (table 1). Likewise, the associated injury profiles were similar with a high rate of lower extremity fractures (29.4\%), followed by spine fractures (26.4\%). Patients with TBI commonly had a subdural hematoma (48.8\%), followed by either a subarachnoid hemorrhage $(43.9 \%)$ or a contusion $(26.8 \%)$. The TBI cohort more likely required operative intervention $(87.8 \%$ vs. $54.9 \%, \mathrm{p}<0.01)$, most commonly for a percutaneous gastrostomy tube $(48.8 \%$ vs. $8.2 \%, \mathrm{p}<0.01)$ and tracheostomy $(41.5 \%$ vs. $10.7 \%, \mathrm{p}<0.01$ ) (table 2 ).

Enoxaparin initiation was delayed in patients with TBI (7.5 vs. 1.5 days after admission, $\mathrm{p}<0.01)$, and a high percentage of these patients received unfractionated heparin prior to enoxaparin initiation $(46.3 \%$ vs. $11.5 \%, \mathrm{p}<0.01)$ (table 3$)$. Furthermore, patients with TBI achieved the target anti-Xa range later ( 11 vs. 5 days after admission, $\mathrm{p}<0.01$ ). The majority of patients in both cohorts $(61.3 \%)$ were not within goal range at the first measurement and required at least one dose adjustment before reaching target anti-Xa trough levels. The median enoxaparin dose that reached the target anti-Xa range was $40 \mathrm{mg}$ every 12 hours for both cohorts. Four patients in each cohort had an inferior vena cava (IVC) filter placed $(9.8 \%$ vs. $3.3 \%, \mathrm{p}=0.11)$. Three patients received an IVC filter in the TBI cohort due to contraindications for immediate therapeutic anticoagulation in the setting of a diagnosed DVT, whereas one patient received a filter because this patient had a previous hypercoagulable state with concurrent bleeding secondary to polytrauma. Similarly, three patients in the non-TBI cohort were diagnosed with a DVT and were not candidates for immediate therapeutic anticoagulation whereas one patient had a previous history of a PE. Imaging studies were obtained due to a clinical suspicion for VTE at similar rates and there was no difference as to when these studies were obtained.

VTE rates were significantly higher among patients with TBI (22.0\% vs. 9.0\%, OR 2.8 (1.1 to 7.5$), \mathrm{p}=0.03)$, and patients with TBI had more proximal DVTs (17.1\% vs. 5.7\%, OR 3.4 (1.1 to 10.3 ), $\mathrm{p}<0.01$ ) (table 4). No patient was diagnosed with a PE. Patients with TBI were more likely to require admission to an ICU ( $92.7 \%$ vs. $73.0 \%, p<0.01)$. Both ICU LOS (14 vs. 3 days, $\mathrm{p}<0.01)$ and hospital LOS (21 vs. 12 days admission, $\mathrm{p}<0.01)$ were prolonged in patients with TBI; however, mortality rates were similar in both cohorts $(4.9 \%$ vs. $2.5 \%, p=0.60)$. Four patients $(9.8 \%)$ had progression of ICH prior to receiving enoxaparin. Importantly, no patients developed progression of their ICH or required operative procedures related to pharmacological prophylaxis during the period in which enoxaparin was administered.

\section{DISCUSSION}

We analyzed that patients with TBI received enoxaparin approximately 7.5 days after admission due in part to a high percentage of these patients receiving unfractionated heparin, and approximately 11 days after admission were required before patients with TBI reached the target prophylactic enoxaparin dose of 40 mg two times per day. After enoxaparin was started the median 
Table 1 Patient characteristics and injury profile

\begin{tabular}{|c|c|c|c|c|}
\hline Characteristic & Total $(n=163)$ & TBI $(n=41)$ & Non-TBI $(n=122)$ & $P$ value \\
\hline Age (years), median & $41(29-60)$ & $47(32.5-59)$ & $40(29-60)$ & 0.68 \\
\hline Male, n (\%) & $110(67.5)$ & $31(75.6)$ & $79(64.8)$ & 0.20 \\
\hline \multicolumn{5}{|l|}{ Race, $n(\%)$} \\
\hline Black & $39(23.9)$ & $8(19.5)$ & $31(25.4)$ & $<0.01$ \\
\hline White & $72(44.2)$ & $16(39.0)$ & $56(45.9)$ & \\
\hline Hispanic & $15(9.2)$ & $2(4.9)$ & $13(10.7)$ & \\
\hline Other/unknown & $37(22.7)$ & $15(36.6)$ & $22(18.0)$ & \\
\hline BMI, median & $24.8(21.5-27.3)$ & $25(21.8-25.8)$ & $24.7(21.1-27.8)$ & 0.57 \\
\hline $\mathrm{CrCl}(\mathrm{mL} / \mathrm{min})$, median & $107.4(72.9-140.2)$ & 111.5 (101.1.-168.0) & $102.5(46.4-125.4)$ & 0.06 \\
\hline \multicolumn{5}{|l|}{ AIS Score, median } \\
\hline Head/neck & $0(0-0)$ & $4(3-4)$ & $0(0-0)$ & $<0.01$ \\
\hline Face & $0(0-2)$ & $0(0-2)$ & $0(0-2)$ & 0.28 \\
\hline Chest & $0(0-3)$ & $0(0-3)$ & $0(0-2)$ & 0.71 \\
\hline Abdomen/pelvis & $1(0-3)$ & $0(0-2)$ & $1(0-3)$ & 0.15 \\
\hline Extremity & $0(0-3)$ & $0(0-3)$ & $0(0-3)$ & 0.99 \\
\hline External & $0(0-1)$ & $1(0-1)$ & $0(0-1)$ & 0.09 \\
\hline ISS, median & $18(11-26)$ & $26(20.5-32)$ & $17(10-22)$ & $<0.01$ \\
\hline ISS without AIS head/neck, median & $17(10-20)$ & $13(5-18)$ & $17(10-22)$ & 0.08 \\
\hline \multicolumn{5}{|l|}{ Mechanism of injury, $n(\%)$} \\
\hline Mechanism of injury, blunt, $\mathrm{n}(\%)$ & $141(87.1)$ & $41(100)$ & $101(82.8)$ & $<0.01$ \\
\hline Automobile vs. pedestrian collision & $22(13.5)$ & $4(9.8)$ & $18(14.8)$ & 0.07 \\
\hline Motorcycle collision & $13(8.0)$ & $6(14.6)$ & $7(5.7)$ & \\
\hline Motor vehicle collision & $40(24.5)$ & $6(14.6)$ & $34(27.9)$ & \\
\hline Fall & $49(30.1)$ & $17(41.5)$ & $32(26.2)$ & \\
\hline Other & $39(23.9)$ & $8(19.5)$ & $31(25.4)$ & \\
\hline \multicolumn{5}{|l|}{ Injury profile, ${ }^{*}$ (\%) } \\
\hline Intra-abdominal solid organ injury & $19(11.7)$ & $4(9.8)$ & $15(12.3)$ & 0.78 \\
\hline Lower extremity fracture & $48(29.4)$ & $11(26.8)$ & $37(30.3)$ & 0.82 \\
\hline Pelvic fracture & $36(22.1)$ & $14(34.1)$ & $22(18.0)$ & 0.05 \\
\hline Spine fracture & $43(26.4)$ & $13(31.7)$ & $30(24.6)$ & 0.49 \\
\hline Upper extremity fracture & $29(17.8)$ & $12(29.3)$ & $17(13.9)$ & 0.09 \\
\hline \multicolumn{5}{|l|}{ Type of TBI, ${ }^{*} n(\%)$} \\
\hline Contusion & - & $11(26.8)$ & - & - \\
\hline Epidural hematoma & - & $6(14.6)$ & - & - \\
\hline Intraparenchymal hemorrhage & - & $4(9.8)$ & - & - \\
\hline Subarachnoid hemorrhage & - & $18(43.9)$ & - & - \\
\hline Subdural hematoma & - & $20(48.8)$ & - & - \\
\hline Other & - & $1(2.4)$ & - & - \\
\hline
\end{tabular}

BMI calculated as weight in kilogram divided by height in meters squared.

* More than one injury type, type of TBI and operative intervention were possible for each patient.

AIS, Abbreviated Injury Scale; BMI, Body Mass Index; CrCl, creatinine clearance; ISS, Injury Severity Score; TBI, traumatic brain injury.

time required to reach a dose within the target anti-Xa range was 3.5 days for both patients with and without TBI. This delay was in part due to the need to increase the enoxaparin dose multiple times, as well as the time required between troughs. These findings provide guidance that a substantial delay exists between when pharmacological prophylaxis is initiated and when adequate prophylaxis is received.

Our result highlight two challenges in pharmacologic prophylaxis after TBI: (1) timely and (2) effective dosing. A subanalysis in a related study ${ }^{23}$ that we performed demonstrated that $48.9 \%$ did not receive enoxaparin, of which $26.4 \%$ received unfractionated heparin, whereas the remainder did not receive any thromboprophylactic agent. Approximately 1.1\% were not started on an agent due to bleeding, whereas $61.8 \%$ were either discharged or had an in-hospital mortality before one could be initiated. In this same study, we found that of the patients that were placed on enoxaparin; $75.0 \%$ did not achieve adequate anti-Xa levels; $6.4 \%$ died, whereas the remainder were discharged before attaining an adequate level. These data provide more insight into the delays that result in adequate dosing.

Although there was no statistical difference as to when a VTE was first diagnosed in this study, diagnosis in the TBI cohort appeared to occur later. This trend may be due to altered mental status secondary to TBI or ventilator dependence, which may impact a clinician's ability to detect a symptomatic VTE, thus leading to later diagnosis. VTE may occur even earlier in patients 
Table 2 Comparison of operative interventions

\begin{tabular}{|c|c|c|c|c|}
\hline & \multicolumn{3}{|l|}{ No. (\%) } & \multirow[b]{2}{*}{$P$ value } \\
\hline & $\begin{array}{l}\text { Total } \\
(\mathrm{N}=163)\end{array}$ & $\mathrm{TBI}(\mathrm{n}=41)$ & $\begin{array}{l}\text { Non-TBI } \\
(n=122)\end{array}$ & \\
\hline \multicolumn{5}{|l|}{ Operative interventions, ${ }^{*} \mathrm{n}(\%)$} \\
\hline $\begin{array}{l}\text { Patients requiring operative } \\
\text { intervention }\end{array}$ & $103(61.7)$ & $36(87.8)$ & $67(54.9)$ & $<0.01$ \\
\hline Cardiothoracic operation & $1(0.6)$ & $1(2.4)$ & 0 & 0.25 \\
\hline Craniectomy/craniotomy & - & $7(17.1)$ & - & - \\
\hline Exploratory laparotomy & $22(13.5)$ & $3(7.3)$ & $19(15.6)$ & 0.28 \\
\hline $\begin{array}{l}\text { Oral and maxillofacial } \\
\text { operation }\end{array}$ & $18(11.0)$ & $8(19.5)$ & $10(8.2)$ & 0.08 \\
\hline $\begin{array}{l}\text { Other othopedic } \\
\text { operation }\end{array}$ & $58(35.6)$ & $19(46.3)$ & $39(32.0)$ & 0.14 \\
\hline $\begin{array}{l}\text { Percutaneous } \\
\text { gastrostomy tube } \\
\text { placement }\end{array}$ & $30(18.4)$ & $20(48.8)$ & $10(8.2)$ & $<0.01$ \\
\hline Spinal operation & $12(7.4)$ & $2(4.9)$ & $10(8.2)$ & 0.72 \\
\hline Tracheostomy & $30(18.4)$ & $17(41.5)$ & $13(10.7)$ & $<0.01$ \\
\hline Vascular repair & $4(2.5)$ & 0 & $4(3.3)$ & 0.57 \\
\hline
\end{tabular}

* More than one injury type, $\mathrm{TBI}$, and operative intervention were possible for each patient.

$\mathrm{TBI}$, traumatic brain injury.

with TBI. Given that the inclusion criteria for this study required patients who remained hospitalized until they reached target anti-Xa trough levels, this cohort represents a subset of patients that were inherently more complex than typical trauma patients. Our data demonstrate that many of these patients had additional injuries and required interventions which may have precluded early pharmacological thromboprophylaxis.

The concern for ICH progression is one reason for delay in timely dosing, although $46.3 \%$ of the patients were started on unfractionated heparin prior to receiving enoxaparin, suggesting that many patients were able to receive pharmacological prophylaxis. Fear of $\mathrm{ICH}$ progression often delays the initiation of enoxaparin, although increasingly it is administered early after brain trauma. ${ }^{23-32}$ Prospective data established that enoxaparin 24 hours after admission was safe for some patients with TBI. ${ }^{24} 25$ Subsequently, the decision to initiate pharmacological prophylaxis was based on whether or not ICH progression was observed on the follow-up CT. ${ }^{263132}$ If ICH progression was noted, exposure to pharmacological prophylaxis predicted further progression. If no ICH progression was observed, then pharmacological prophylaxis was encouraged. ${ }^{263132}$ The rate of ICH progression was about $10 \%$ whether or not pharmacological prophylaxis was initiated. ${ }^{26}$ When early pharmacological prophylaxis is initiated after TBI, there is a lower VTE rate with no difference in rate of late neurosurgical intervention..$^{27} 3132$

Since approximately half of the patients with TBI studied were initiated first on unfractionated heparin prophylaxis, the belief that unfractionated heparin is somehow safer than enoxaparin persists despite evidence that the opposite may be true as unfractionated heparin is associated with a higher rate of $\mathrm{ICH}$ progression. ${ }^{3}$ As enoxaparin has increased bioavailability, longer plasma half life, more predictable pharmacokinetics and pharmacodynamics, ${ }^{8}$ interacts less with platelets, and has a lower incidence of heparin-induced thrombocytopenia compared with unfractionated heparin ${ }^{33}$ the belief that unfractionated heparin is safer is unfounded.

Unfractionated heparin at $5000 \mathrm{U}$ three times a day continues to be proposed as 'non-inferior' to enoxaparin in part due to a trial that concluded the two medication may have similar VTE rates. ${ }^{12}$ This trial was underpowered to demonstrate the actual difference in the VTE rate as it predicted a VTE rate of $44 \%$ for unfractionated heparin and 31\% for enoxaparin instead of the observed rate of $8.2 \%$ for unfractionated heparin and $5.1 \%$ for enoxaparin $(p=0.2) .{ }^{8}{ }^{12}$ In addition, the trial was not powered to detect a difference in the rate of PE or HIT, both of which impact the complication rate and healthcare costs. ${ }^{8} 10$ More recently, enoxaparin $30 \mathrm{mg}$ two times per day was established as superior to unfractionated heparin $5000 \mathrm{U}$ three times a day at reducing VTE. ${ }^{8} 1011$

The optimal dose for many patients in this study was $40 \mathrm{mg}$ two times per day. At our institution, all trauma patients are started on enoxaparin $40 \mathrm{mg}$ two times per day unless one or more of the following exclusions apply: TBI, spinal cord injury, suspicion for ongoing bleeding, evidence of acute or chronic kidney disease, or 65 years of age or older. Our data demonstrate that the majority of patients with TBI require enoxaparin $40 \mathrm{mg}$ two times per day or higher. The decision to initiate patients with TBI with enoxaparin $40 \mathrm{mg}$ two times per day, in an effort to minimize the time to achieve adequate thromboprophylaxis, will require further investigation. Customized dosing using the

Table 3 Details regarding enoxaparin administration

\begin{tabular}{|c|c|c|c|c|}
\hline & Total $(\mathrm{N}=163)$ & TBI $(n=41)$ & Non-TBI $(n=122)$ & $P$ value \\
\hline Time to initiate enoxaparin, median $\mathrm{d}$ & $2(1-6)$ & $7.5(3-10)$ & $1.5(1-4)$ & $<0.01$ \\
\hline Days to first anti-Xa level drawn, median d & $4(2-7)$ & $9(5-11.5)$ & $3(2-6)$ & $<0.01$ \\
\hline Within goal at first measure, $\mathrm{n}(\%)$ & $63(38.7)$ & $15(36.6)$ & $48(39.3)$ & 0.75 \\
\hline Days to reach goal (from admission), median $d$ & $6(6-13)$ & $11(7-16)$ & $5(2-10)$ & $<0.01$ \\
\hline Dose adjustments to reach goal, median $\mathrm{n}$ & $1(0-1)$ & $1(0-2)$ & $1(0-1)$ & 0.61 \\
\hline Optimal dose based on anti-Xa levels (mg), median & $40(30-40)$ & $40(30-50)$ & $40(30-40)$ & 0.73 \\
\hline Patients given prophylactic unfractionated heparin prior to enoxaparin, $\mathrm{n}(\%)$ & $33(20.2)$ & $19(46.3)$ & $14(11.5)$ & $<0.01$ \\
\hline Days to initiate prophylactic unfractionated heparin, median d & $3(1-3)$ & $3(2-4)$ & $1(0-3)$ & 0.01 \\
\hline Patients who underwent IVC filter placement, $\mathrm{n}(\%)$ & $8(4.9)$ & $4(9.8)$ & $4(3.3)$ & 0.11 \\
\hline Duplex ultrasonography ordered based on clinical suspicion, $\mathrm{n}(\%)$ & $50(30.7)$ & $13(31.7)$ & $37(30.3)$ & 0.87 \\
\hline Days to first duplex ultrasonography performed, median d & $7.5(5-12)$ & $10(6.5-13)$ & $6(4-11)$ & 0.07 \\
\hline Chest CT angiography ordered, $\mathrm{n}(\%)$ & $22(13.5)$ & $6(14.6)$ & $16(13.1)$ & 0.81 \\
\hline Days to first chest $\mathrm{CT}$ angiography based on clinical suspicion, median $\mathrm{d}$ & $8(5-18)$ & $16.5(8-22)$ & $7(5-12)$ & 0.25 \\
\hline
\end{tabular}

IVC, inferior vena cava; TBI, traumatic brain injury. 
Table 4 Outcomes in patients with TBI and patients without TBI

\begin{tabular}{|c|c|c|c|c|c|}
\hline & Total $(\mathrm{N}=163)$ & TBI $(n=41)$ & Non-TBI $(n=122)$ & OR or mean difference $(95 \% \mathrm{Cl})$ & $P$ value \\
\hline \multicolumn{6}{|l|}{ VTE outcomes } \\
\hline VTE, n (\%) & $20(12.3)$ & $9(22.0)$ & $11(9.0)$ & 2.8 (1.1 to 7.5$)$ & 0.03 \\
\hline Proximal DVT & $14(8.6)$ & $7(17.1)$ & $7(5.7)$ & $3.4(1.1$ to 10.3$)$ & $<0.05$ \\
\hline Distal DVT & $16(9.8)$ & $7(17.1)$ & $9(7.4)$ & $2.6(0.9$ to 7.5$)$ & 0.12 \\
\hline $\mathrm{PE}$ & 0 & 0 & 0 & 0 & $>0.99$ \\
\hline Days to first VTE diagnosis (from admission), median d & $15(8.5-18)$ & $16(13.5-20)$ & $7(4-17)$ & $5.2(-0.4$ to 10.9$)$ & 0.09 \\
\hline \multicolumn{6}{|l|}{ Blood transfusions } \\
\hline Required blood while on enoxaparin, n (\%) & $20(12.3)$ & $4(9.8)$ & $16(13.1)$ & $0.7(0.2$ to 2.3$)$ & 0.57 \\
\hline \multicolumn{6}{|l|}{ Overall outcomes } \\
\hline ICU LOS, median d & $4(1-12)$ & $14(4-20.5)$ & $3(1-7)$ & 8.8 (5.2 to 12.5$)$ & $<0.01$ \\
\hline Hospital LOS, median d & $14(7-23)$ & $21(14-34)$ & $12(6-20)$ & 12.3 (4.0 to 20.5 ) & $<0.01$ \\
\hline Mortality, n (\%) & $5(3.1)$ & $2(4.9)$ & $3(2.5)$ & $2.0(0.3$ to 12.6$)$ & 0.60 \\
\hline
\end{tabular}

DVT, deep vein thrombosis; ICU, intensive care unit; LOS, length of stay; PE, pulmonary embolism; TBI, traumatic brain injury; VTE, venous thromboembolism.

patient's creatinine dosing may result in better optimized initial enoxaparin dosing. ${ }^{3435}$

This study was limited by its small size and lack of randomization. At times, disagreement occurred between the trauma and neurosurgical services regarding appropriate pharmacological prophylaxis for patients with TBI. This study could not capture the reasons for missed enoxaparin doses. As noted, the two cohorts were not similar with regard to injury severity so the higher VTE rate in patients with TBI could be attributable to reasons other than delayed or inadequate pharmacological prophylaxis. Importantly, the objective of this article was to characterize the delay until an adequate dose of enoxaparin was received in patients with and without brain trauma and not to compare the VTE rates between these cohorts. Despite these limitations, we demonstrated that unfractionated heparin and low enoxaparin doses could be reasons for higher VTE rates in patients with TBI. Although the Brain Trauma Foundation established that there is insufficient evidence to support recommendations regarding the preferred agent, dose, or timing of pharmacological prophylaxis, these recommendations may be outdated. ${ }^{36}$ Partly due to the findings of this study, we have collaborated with our neurointensivist and neurosurgical colleagues at our institution to implement earlier initiation of enoxaparin.

In conclusion, based on anti-Xa levels 11 days after admission were required before patients with TBI received an adequate enoxaparin dose for pharmacological prophylaxis due to delays in its initiation and because unfractionated heparin was frequently used as an intermediate agent. The median enoxaparin dose required to reach target anti-Xa levels for both patients with TBI and patients without TBI was $40 \mathrm{mg}$ two times per day. The early administration of enoxaparin titrated by anti-Xa trough levels should be strongly considered for patients with TBI. A prospective randomized clinical trial with a larger TBI cohort is recommended to improve VTE prophylaxis for this population.

Acknowledgements We thank the Cedars-Sinai Medical Center and Trauma Registry for their support in this project.

Contributors Study conception and design: NKD and EJL; acquisition of data: NKD GC, and RM; analysis and interpretation of data: NKD, YMH, NB, and FY; drafting of article: NKD, YMH, GC, EJL; critical revision: NB, FY, and RM.

Funding The authors have not declared a specific grant for this research from any funding agency in the public, commercial or not-for-profit sectors.

Competing interests None declared.

Patient consent for publication Not required
Ethics approval This study was approved by the Cedars-Sinai Medical Center Institutional Review Board with the requirement for informed consent formally waived.

Provenance and peer review Not commissioned; externally peer reviewed.

Data availability statement Data may be obtained from a third party and are not publicly available.

Open access This is an open access article distributed in accordance with the Creative Commons Attribution Non Commercial (CC BY-NC 4.0) license, which permits others to distribute, remix, adapt, build upon this work non-commercially, and license their derivative works on different terms, provided the original work is properly cited, appropriate credit is given, any changes made indicated, and the use is non-commercial. See: http://creativecommons.org/licenses/by-nc/4.0/.

\section{REFERENCES}

1 Reiff DA, Haricharan RN, Bullington NM, Griffin RL, McGwin G, Rue LW. Traumatic brain injury is associated with the development of deep vein thrombosis independent of pharmacological prophylaxis. J Trauma 2009:66:1436-40.

2 Valle EJ, Van Haren RM, Allen CJ, Jouria JM, Bullock MR, Schulman Cl, Namias $\mathrm{N}$, Livingstone $A S$, Proctor KG. Does traumatic brain injury increase the risk for venous thromboembolism in polytrauma patients? J Trauma Acute Care Surg 2014;77:243-50

3 Abdel-Aziz H, Dunham C, Malik RJ, Hileman BM. Timing for deep vein thrombosis chemoprophylaxis in traumatic brain injury: an evidence-based review. Crit Care 2015;19:96.

4 Mesa Galan LA, Egea-Guerrero JJ, Quintana Diaz M, Vilches-Arenas A. The effectiveness and safety of pharmacological prophylaxis against venous thromboembolism in patients with moderate to severe traumatic brain injury. J Trauma Acute Care Surg 2016:81:567-74.

5 Scudday T, Brasel K, Webb T, Codner P, Somberg L, Weigelt J, Herrmann D, Peppard W. Safety and efficacy of prophylactic anticoagulation in patients with traumatic brain injury. J Am Coll Surg 2011:213:148-53.

6 M. Foreman P, G. R. Schmalz P, Griessenauer CJ. Chemoprophylaxis for venous thromboembolism in traumatic brain injury: a review and evidence-based protocol. Clin Neurol Neurosurg 2014;123:109-16.

7 Geerts WH, Jay RM, Code KI, Chen E, Szalai JP, Saibil EA, Hamilton PA. A comparison of low-dose heparin with low-molecular-weight heparin as prophylaxis against venous thromboembolism after major trauma. N Engl J Med Overseas Ed 1996:335:701-7

8 Jacobs BN, Cain-Nielsen AH, Jakubus JL, Mikhail JN, Fath JJ, Regenbogen SE, Hemmila MR. Unfractionated heparin versus low-molecular-weight heparin for venous thromboembolism prophylaxis in trauma. J Trauma Acute Care Surg 2017:83:151-8.

9 Benjamin E, Recinos G, Aiolfi A, Inaba K, Demetriades D. Pharmacological thromboembolic prophylaxis in traumatic brain injuries: low molecular weight heparin is superior to unfractionated heparin. Ann Surg 2017;266:463-9.

10 Byrne JP, Geerts W, Mason SA, Gomez D, Hoeft C, Murphy R, Neal M, Nathens AB. Effectiveness of low-molecular-weight heparin versus unfractionated heparin to prevent pulmonary embolism following major trauma: a propensity-matched analysis. J Trauma Acute Care Surg 2017;82:252-62.

11 Ley EJ, Brown CVR, Moore EE, Sava JA, Peck K, Ciesla DJ, Sperry JL, Rizzo AG, Rosen NG, Brasel KJ, et al. Updated guidelines to reduce venous thromboembolism in trauma patients: a Western trauma association critical decisions algorithm. J Trauma Acute Care Surg 2020;89:971-81. 
12 Olson EJ, Bandle J, Calvo RY, Shackford SR, Dunne CE, Van Gent J-M, Zander AL, Sikand $\mathrm{H}$, Bongiovanni MS, Sise MJ, et al. Heparin versus enoxaparin for prevention of venous thromboembolism after trauma: a randomized noninferiority trial. J Trauma Acute Care Surg 2015;79:961-8.

13 Ko A, Harada MY, Barmparas G, Chung K, Mason R, Yim DA, Dhillon N, Margulies DR Gewertz BL, Ley EJ. Association between enoxaparin dosage adjusted by Anti-Factor Xa Trough level and clinically evident venous thromboembolism after trauma. JAMA Surg 2016;151:1006-13.

14 Singer GA, Riggi G, Karcutskie CA, Vaghaiwalla TM, Lieberman HM, Ginzburg E, Namias N, Lineen EB. Anti-Xa-guided enoxaparin thromboprophylaxis reduces rate of deep venous thromboembolism in high-risk trauma patients. J Trauma Acute Care Surg 2016;81:1101-8.

15 Lin H, Faraklas I, Saffle J, Cochran A. Enoxaparin dose adjustment is associated with low incidence of venous thromboembolic events in acute burn patients. J Trauma 2011;71:1557-61.

16 Rodier SG, Bukur M, Moore S, Frangos SG, Tandon M, DiMaggio CJ, AyoungChee P, Marshall GT. Weight-based enoxaparin with anti-factor Xa assay-based dose adjustment for venous thromboembolic event prophylaxis in adult trauma patients results in improved prophylactic range targeting. Eur J Trauma Emerg Surg 2021;47:145-51.

17 Walker CK, Sandmann EA, Horyna TJ, Gales MA. Increased enoxaparin dosing for venous thromboembolism prophylaxis in general trauma patients. Ann Pharmacother 2017:51:323-31.

18 Bickford A, Majercik S, Bledsoe J, Smith K, Johnston R, Dickerson J, White T. Weightbased enoxaparin dosing for venous thromboembolism prophylaxis in the obese trauma patient. Am J Surg 2013;206:847-52.

19 Nunez JM, Becher RD, Rebo GJ, Farrah JP, Borgerding EM, Stirparo JJ, Lauer C, Kilgo P, Miller PR. Prospective evaluation of Weight-Based prophylactic enoxaparin dosing in critically III trauma patients: adequacy of AntiXa levels is improved. Am Surg 2015;81:605-9.

20 Berndtson AE, Costantini TW, Lane J, Box K, Coimbra R. If some is good, more is better: an enoxaparin dosing strategy to improve pharmacologic venous thromboembolism prophylaxis. J Trauma Acute Care Surg 2016:81:1095-100.

21 Cronin BJ, Godat LN, Berndtson AE, Pham A, Kolan S, Box K, Lee JG, Costantini TW. Anti-Xa guided enoxaparin dose adjustment improves pharmacologic deep venous thrombosis prophylaxis in burn patients. Burns 2019;45:818-24

22 Dhillon NK, Smith EJT, Gillette E, Mason R, Barmparas G, Gewertz BL, Ley EJ. Trauma patients with lower extremity and pelvic fractures: should anti-factor Xa Trough level guide prophylactic enoxaparin dose? Int I Surg 2018;51:128-32.

23 Dhillon NK, Barmparas G, Lin TL, Linaval NT, Yang AR, Sekhon HK, Mason R, Margulies $D R$, Gewertz BL, Ley EJ. A systems-based approach to reduce deep venous thrombosis and pulmonary embolism in trauma patients. World J Surg 2021;45:738-45.

24 Norwood SH, Berne JD, Rowe SA, Villarreal DH, Ledlie JT. Early venous thromboembolism prophylaxis with enoxaparin in patients with blunt traumatic brain injury. J Trauma 2008:65:1021-7.
25 Norwood SH, McAuley CE, Berne JD, Vallina VL, Kerns DB, Grahm TW, Short K, McLarty JW. Prospective evaluation of the safety of enoxaparin prophylaxis for venous thromboembolism in patients with intracranial hemorrhagic injuries. Arch Surg 2002;137:696-701.

26 Levy AS, Salottolo K, Bar-Or R, Offner P, Mains C, Sullivan M, Bar-Or D. Pharmacologic thromboprophylaxis is a risk factor for hemorrhage progression in a subset of patients with traumatic brain injury. J Trauma 2010;68:886-94.

27 Byrne JP, Mason SA, Gomez D, Hoeft C, Subacius H, Xiong W, Neal M, Pirouzmand $F$, Nathens $A B$. Timing of pharmacologic venous thromboembolism prophylaxis in severe traumatic brain injury: a Propensity-Matched cohort study. J Am Coll Surg 2016;223:621-31.

28 Störmann P, Osinloye W, Freiman TM, Seifert V, Marzi I, Lustenberger T. Early chemical thromboprophylaxis does not increase the risk of intracranial hematoma progression in patients with isolated severe traumatic brain injury. World I Surg 2019:43:2804-11.

29 Phelan HA, Wolf SE, Norwood SH, Aldy K, Brakenridge SC, Eastman AL, Madden CJ, Nakonezny PA, Yang L, Chason DP, et al. A randomized, double-blinded, placebocontrolled pilot trial of anticoagulation in low-risk traumatic brain injury: the delayed versus early enoxaparin prophylaxis I (DEEP I) study. J Trauma Acute Care Surg 2012;73:1434-41.

30 Jamjoom $A A B$, Jamjoom $A B$. Safety and efficacy of early pharmacological thromboprophylaxis in traumatic brain injury: systematic review and meta-analysis. $J$ Neurotrauma 2013;30:503-11.

31 Farooqui A, Hiser B, Barnes SL, Litofsky NS. Safety and efficacy of early thromboembolism chemoprophylaxis after intracranial hemorrhage from traumatic brain injury. J Neurosurg 2013;119:1576-82.

32 Saadeh Y, Gohil K, Bill C, Smith C, Morrison C, Mosher B, Schneider P, Stevens P, Kepros JP. Chemical venous thromboembolic prophylaxis is safe and effective for patients with traumatic brain injury when started 24 hours after the absence of hemorrhage progression on head CT. J Trauma Acute Care Surg 2012;73:426-30.

33 Fareed J, Hoppensteadt D, Walenga J, Iqbal O, Ma Q, Jeske W, Sheikh T. Pharmacodynamic and pharmacokinetic properties of enoxaparin : implications for clinical practice. Clin Pharmacokinet 2003:42:1043-57.

34 Veatch J, Hashim Y, Dhillon NK, Toscano S, Mason R, Lin T-L, Barmparas G, Ley EJ. Which trauma patients require lower enoxaparin dosing for venous thromboembolism prophylaxis? Am Surg 2020;86:1424-7

35 Hashim YM, Dhillon NK, Veatch JM, Barmparas G, Ley EJ. Clinical characteristics associated with higher enoxaparin dosing requirements for venous thromboembolism prophylaxis in trauma patients. Am Surg 2020:000313482097957.

36 Bratton SL, Chestnut RM, Ghajar J, McConnell Hammond FF, Harris OA, Hartl R, et al. Brain Trauma FoundationAmerican Association of Neurological SurgeonsCongress of Neurological SurgeonsJoint Section on Neurotrauma and Critical Care, AANS/CNS. Guidelines for the management of severe traumatic brain injury. V. deep vein thrombosis prophylaxis. J Neurotrauma 2007;24 Suppl 1:S32-6. 